\title{
COVID-19, una oportunidad para crecer en humanidad
}

\section{COVID-19, an opportunity to grow in humanity}

Recibido el 17/ 09/ 2020. Revisión del 25/ 09/ 2020. Aceptado 27/09/2020

María Teresa Briozzo Pereyra (CMR)

tbriozzo@ucss.edu.pe

https://orcid.org/0000-0002-0616-4757

Universidad Católica Sedes Sapientiae - UCSS

\section{Resumen}

En una breve introducción se indica el tema de estudio y a su vez se señala el enfoque antropológico ético del mismo. Cuando se atraviesan momentos críticos de la historia, se evidencia lo mejor y también lo peor que se encuentra en el hombre. La pandemia de la COVID-19 también nos mostró esta realidad: humanidad, solidaridad, heroísmo, pero también indiferencia, individualismo. Se realiza una mirada a la tormenta inesperada que zarandea la humanidad y se percibe una humanidad distraída, confiada en sus recursos y ocupada en sus intereses, creyéndose omnipotente. Se ha observado cómo el Papa Francisco sale al encuentro de la crisis orientando. Junto a él, se ha encontrado una serie de autores que reflexionan sobre la coyuntura, exponiendo diversos aspectos del desafío de la pandemia actual. A su vez, se reconoce la necesidad de un cambio en la persona humana; es necesario que pueda crecer en humanidad para reconocer su vulnerabilidad y para enfrentar trágicos imprevistos con dignidad y solidaridad. En la resolución de la pandemia se evidencia la incidencia del sistema económico e ideológico actual, basado en el consumismo, lucro e individualismo. Se destaca la necesidad de un cambio de paradigma; lo que llamamos normalidad, no es la normalidad de una vida humana que utiliza al otro y destruye su hábitat. Se reconoce una desmesura antropológica de cortas miras, que lleva al egoísmo y a la catástrofe ecológica.

Palabras clave: COVID-19, pandemia, humanidad, persona, normalidad, Francisco.

\begin{abstract}
A brief introduction indicates the subject of study and at the same time points out the anthropological and ethical approach to it. When we go through critical moments in history, the best and also the worst found in man becomes evident. The COVID-19 pandemic also showed us this reality: humanity, solidarity, heroism, but also indifference, individualism. A glance is made at the unexpected storm that is shaking humanity and a distracted humanity is perceived, trusting in its resources, and occupied in its interests, believing itself omnipotent. It has been observed how Pope Francis meets the crisis by giving guidance. Along with him, a series of authors have been found who reflect on the situation, exposing various aspects of the challenge of the current pandemic. At the same time, the need for a change in the human person is recognized; It is necessary for them to grow in humanity to recognize their vulnerability and to face tragic unforeseen events
\end{abstract}


with dignity and solidarity. The resolution of the pandemic demonstrates the impact of the current economic and ideological system, based on consumerism, profit and individualism the need for a paradigm shift is highlighted; what we call normality is not the normality of a human life that uses the other and destroys their habitat. A short-sighted anthropological excess is recognized, leading to selfishness and ecological catastrophe.

Keywords: COVID-19, pandemic, humanity, person, normalcy, Francisco

\section{Introducción}

La idea del mundo en cuarentena es absolutamente inaudita. Quizás es por eso que muchos hombres todavía no la toman con seriedad. Según Tolentino de Mendonça (2020) en la actualidad, en una sociedad tecnológica, científica, que se considera omnipotente, el término «cuarentena» la remite a tiempos pasados, que la modernidad ha superado definitivamente (p. 173).

Sin embargo, precisamente cada momento crítico de la historia se ha necesitado de un nuevo tipo de hombre, así lo han advertido personalidades clarividentes. Cuando terminó la Segunda Guerra mundial, Romano Guardini (citado en López Quintás, 1963) advirtió la necesidad apremiante de un nuevo estilo de pensar y de sentir, es decir la figura de un hombre nuevo:

Un nuevo tipo de hombre debe surgir, un hombre de profunda espiritualidad, de un nuevo sentido de la libertad y la intimidad, una nueva conformación y poder de configuración (...) Lo que necesitamos no es menos técnica sino más; mejor dicho: una técnica más fuerte, más reflexiva, más 'humana'. Más ciencia, pero más espiritual, mejor conformada. Más energía económica y política, pero más desarrollada, más madura, más consciente de su responsabilidad. (p. 62)

Hace más de 50 años Pablo VI (1967), observaba la desigualdad entre los hombres por un sistema económico nacional e internacional injusto, considerado un verdadero imperialismo del dinero que no permitía el desarrollo de los pueblos en vías de desarrollo. Es en este contexto, el Papa publica la Encíclica Populorum Progressio (PP), en ella hablaba sobre la urgencia de un desarrollo humano integral. Animaba a caminar hacia un humanismo nuevo: "Si para llevar a cabo el desarrollo se necesitan técnicos, cada vez en mayor número, para este mismo desarrollo se exige más todavía pensadores de reflexión profunda que busquen un humanismo nuevo" (PP 20).

No obstante, a lo largo de estos años no parecen haber cambiado mucho las cosas; el Papa Francisco (2018) en la Conferencia internacional sobre los derechos humanos en el mundo, señalaba que poniendo la atención nuestras sociedades contemporáneas, encontramos inmensas contradicciones que nos llevan a preguntarnos si en realidad la igual dignidad de todos los seres humanos, sea reconocida, respetada, protegida y promovida en todas las circunstancias.

En efecto, constata Francisco (2018), que hoy continúan existiendo numerosas formas de injusticia, a causa de visiones reductivas sobre el hombre y por un modelo económico basado en las ganancias, que no duda en explotar, descartar e incluso matar al hombre. En consecuencia, el Papa Francisco (2018) evidencia que, mientras una parte de

Contacto: revistaeduca@umch.edu.pe ISSN : 2617-0337 revistas.umch.edu.pe/ 
la humanidad vive en opulencia, otra parte ve su propia dignidad desconocida, despreciada o pisoteada y sus derechos fundamentales ignorados o violados (p. 1).

Ante estos graves fenómenos, el Papa se cuestiona y cuestiona a todos los hombres. Por eso, anima a cada uno a contribuir y comprometerse con coraje y determinación, para que se respeten los derechos fundamentales de cada persona, especialmente de las "invisibles": de los muchos que viven en los márgenes de la sociedad o son descartados.

\section{Una Tormenta Inesperada zarandea a la Humanidad}

En el año 2020 acontece un evento, a nivel mundial, de grandes proporciones; la Covid19 que ha obligado a la humanidad al aislamiento social y a la paralización de casi todas las actividades. Se trata ciertamente de una tragedia en la que muchos seres humanos perdieron la vida.

Al respecto, Carrón (2020a) reflexiona señalando que la pandemia nos ha mostrado que muchos hemos vivido en una burbuja sintiéndonos protegidos de los golpes de la vida. Vivimos distraídos, entretenidos, creyendo que todo estaba bajo control. Pero la realidad de estos acontecimientos nos ha llamado a responder y a preguntarnos sobre nuestra existencia (p. 9).

Más aún, explica el novelista y columnista español, Gonzáles Sainz (citado en Carrón, 2020a), que se tiene la tendencia a disfrazar la realidad:

El hábito de sustitución de las cosas y los hechos por su uso estratégicamente fraudulento, de la realidad por la ideología, de la verdad por la costumbre impune del embuste y de lo crucial por la vanidad nos pone en las peores condiciones para enfrentarnos a la venganza de la realidad en toda su regla. (pp. 11-12)

Sin embargo, señala Carrón (2020a) que cuanto más agudamente nos golpea una situación, más se agudiza la mirada de la razón, para tratar de comprender, sin conformarse con soluciones superficiales. Las cosas revelan todo su sentido a una razón comprometida con todos los sentidos y afectos. En realidad, el miedo y el asombro constituye un factor esencial para ver con mayor profundidad. Esto es lo que ahora se está comprobando (p. 13).

Es decir, se debe hacer una lectura clara de la realidad, sin prejuicios, para entender quiénes somos y qué demanda esta situación específica a cada uno de los hombres, como seres racionales, inteligentes conscientes y libres.

Diría Giussani (2008): "Ese acontecimiento singular de la naturaleza, en la cual esta se revela como exigencia operativa de explicar la realidad en todos sus factores, de manera que el hombre se vea introducido en la verdad de las cosas" (p. 141).

Pero, en verdad si se observa atentamente esta insólita realidad, se trata también de una nueva oportunidad para realizar una profunda reflexión sobre el estilo de vida de cada uno y de la sociedad. También es una coyuntura en que se evidencia lo que estaba escondido y que ahora se vuelve relevante: esta experiencia puede hacer renacer una humanidad nueva más solidaria; hoy existen muchos más recursos para crecer en humanidad. 
Quien escape a la realidad de los acontecimientos que vivimos en esta pandemia, comenta Carrón (2020a), no podrá experimentar profundamente la agudización de la razón y del corazón que nos hace humanos (p. 15).

Efectivamente, en estos tiempos difíciles, se ha podido evidenciar también un aumento de humanidad, de esa que no se difunde en los periódicos; largas colas en las casas de transferencia de dinero, en donde se recibe dinero del extranjero y se envía dinero al extranjero, pequeñas cantidades, para afrontar la situación. Es una clara manifestación de esa reserva subterránea de humanidad que existe en la historia, que no es otra que la presencia viva de Cristo, caminando en esta trágica época.

Y agrega Galimberti (citado en Carrón, 2020a):

En esta condición insólita en que nos hallamos, paralizados en nuestras actividades cotidianas, en este estado de desorientación, ¿no haría falta que para entrar en la interioridad... para saber ¿quiénes somos?, ¿qué hacemos en este mundo, qué sentido tiene la vida? Estas reflexiones... nos ayudarían para ser verdaderamente hombres. (p. 16)

Habría que percibir la cuarentena con nuevos ojos, para entenderla como un espacio abierto para ser, en todas sus dimensiones, en particular la dimensión trascendente del hombre. En efecto, el Concilio Vaticano II (1965) recuerda que el hombre ha sido creado con la capacidad de conocerse a sí mismo, con la posibilidad de conocer y amar a su Creador (GS 12).

Al respecto, Tolentino de Mendonça (2020) recuerda que Rodin realizó una escultura de piedra, consistente en dos manos que se tocan y estiran para que los dedos en el punto más alto formen un arco, que llamó la Catedral:

¿Qué es una catedral? No es solo un territorio sagrado exterior a donde nuestros pies nos llevan. También se llega a una catedral con nuestras manos abiertas, disponibles y suplicantes, dondequiera estemos. Porque donde está el ser humano, herido con la finitud y el infinito es el eje de una catedral. Donde podemos realizar la experiencia vital de búsqueda y escucha para la cual la pura inmanencia no es la respuesta. (p. 29)

En tiempo de pandemia es necesario también, elevar la mirada a Dios, no para pedirle que haga lo que al hombre le toca hacer; tampoco el hombre se dirige a Dios en una tragedia por sentirse castigado, no. Con Jesucristo y desde él, nuestra vida se recapitula y se resignifica la historia concreta de la pandemia; en Cristo la misma pandemia se vuelve una nueva oportunidad de salvación humana (Ef. 1,10).

\section{Francisco sale al Encuentro de la Humanidad orientando}

Precisamente, en este contexto de pandemia, el Papa Francisco (2020), en diversos documentos, ofrece oportunas y extensas reflexiones que parecen dar orientaciones para que, al salir de ella seamos más grandes en humanidad.

Al respecto, el Cardenal Michael Czerny (2020) considera que el Papa Francisco, en sus mensajes, discursos, cartas, durante la pandemia tienen dos objetivos: 1. Sugerir una dirección, algunas claves para reconstruir un mundo mejor que podría nacer de esta 
crisis de la humanidad. 2. Sembrar esperanza en medio de tanto sufrimiento y desconcierto (p. 3).

Esperanza que necesitaba ser alentada. En efecto, fueron por demás elocuentes las imágenes de las ciudades turísticas más concurridas del mundo, convertidas en un desierto desolador. También, la imagen del Papa Francisco (2020), en la Vigilia Pascual, ante la Plaza San Pedro, absolutamente vacía y en un silencio ensordecedor.

A su vez, es significativo destacar el contexto litúrgico en que se dan los mensajes, se trata de la Pascua, la fiesta central del cristianismo. Por eso el pronunciamiento más elocuente y solemne de la Iglesia Católica, es el Mensaje Pascual en el cual el Papa Francisco (2020a) se dirige a los cristianos, pero también a todos los hombres del mundo:

Hoy resuena en todo el mundo el anuncio de la Iglesia: ¡Jesucristo ha resucitado! ... En la noche de un mundo que ya enfrentaba desafíos cruciales y que ahora se encuentra abrumado por la pandemia, que somete a nuestra gran familia humana a una dura prueba. (p. 1)

Sin embargo, rápidamente el Papa advierte no sólo las dimensiones de acontecimiento, sino el fruto que se debería sacar de esta circunstancia.

Por ello, Francisco (2020d) hace una primera y elemental constatación que teníamos como al margen:

Nos sorprendió una tormenta inesperada y furiosa. Nos dimos cuenta de que estábamos en la misma barca, todos frágiles y desorientados; pero al mismo tiempo, importantes y necesarios, todos llamados a remar juntos, todos necesitados de confortarnos mutuamente. (p. 19)

La experiencia, observa Francisco (2020a), hace reconocer que no se puede seguir en la indiferencia, en el egoísmo, en la división en el olvido, el individualismo acostumbrado, es decir cada uno por su cuenta y entretenidos en sus intereses, sino que sólo juntos se puede salir adelante (p. 1).

Es realista esta primera reflexión de Francisco (2020d) nos dimos cuenta de que estábamos en la misma barca de este mundo, todos frágiles y desorientados, pero estamos llamados a remar juntos. Y justamente lo contrario es lo que se venía haciendo; sin embargo, si no se rema juntos, no se avanza en la lucha contra la pandemia (p. 19).

Agrega Jiménez-Bósquez (2020) enfrentamos una cantidad de hechos que nos afecta individual, comunitaria y globalmente:

Lo que está pasando nos interpela y hace que nuestra existencia se sienta en el "punto cero" (...) Sucede que nos estamos dando cuenta de que lo único que podemos hacer para proteger nuestra vida y la de los demás es cuidarnos (...) Se nos recuerda que, sin cuidado, sin dinámicas y lógicas de convivencia fundadas en el cuidado y la empatía de los unos por los otros, la vida es un proyecto inviable. (p. 8)

En síntesis, continúa el autor, nos guste o no somos vulnerables. En consecuencia, una nota decisiva de la pandemia es reconocer que somos interdependientes, no existimos individualmente. Es curioso que solo en momentos y circunstancias trágicos volvamos, 
por obligación, a recordar la innegociable necesidad del otro. Ojalá, que el tener la muerte rondando por las calles nos enseñe a amar la vida y vivirla con autenticidad (JiménezBósquez, 2020, p. 9).

Sin embargo, no se puede encubrir las inconsistencias humanas actuales. Ante todo, se ha visto en el aprovechamiento de la situación de pandemia, para sacar ventajas personales aún a costa de la vida del otro. También se manifiesta, en la imperiosa necesidad de aturdirse; se ha visto que, en pleno estado de emergencia sanitaria, en diversos lugares del país se organizan fiestas, como si nada pasara, arriesgando la vida personal y la de otros, incluso exponiéndose a tragedias. ¿Qué le está pasando al hombre? ¿qué tiene que tapar con música y alcohol, aunque sea por unas horas?

En este sentido, son acertadas las reflexiones de Carrón (2020b) cuando sostiene que el nihilismo actual se presenta como una sospecha acerca del valor de la vida, de su sentido y de la utilidad de la propia existencia y esto se manifiesta en un vacío que esconde una sutil desesperación (pp. 5-6). Es un síntoma revelador; aunque ahora no es el lugar para desarrollar, pero es una evidencia de la crisis de la existencia de algunos hombres.

En cambio, insiste Jiménez-Bósquez (2020), enfatizando la importancia del otro:

Yo soy porque son los otros, la pandemia enseña que somos interdependientes. El hombre no tiene libertad y autonomía absoluta depende del comportamiento de otros. Sólo a través del otro puedo salir de mí mismo y descubrir la propia identidad. La vida humana y su posibilidad, requiere de la compasión y la solidaridad de todos. Nuestras sociedades no pueden seguir como estaban, necesitamos una nueva humanidad. (pp. 910)

Por consiguiente, señala Francisco (2020a), que en esta situación no debe haber lugar para la indiferencia, porque el mundo entero está sufriendo y hay que luchar unidos para afrontar la pandemia. Particularmente, el pensamiento de Francisco se dirige a los pobres, a quienes viven en las periferias a los prófugos y a los que no tienen un hogar. Y culmina solicitando que estos hermanos más débiles, que habitan en las ciudades y periferias de cada rincón del mundo, no se sientan solos (p. 2).

Es imprescindible y urgente un cambio de vida y actitud, personal y social, es la hora de la solidaridad real, manifestada con hechos concretos.

Desde hace algunos años ya constataba Francisco (2015) que, si bien es necesaria la crítica al antropomorfismo desviado en la ecología, no se debería olvidar el valor de las relaciones entre las personas. En efecto, considera el Papa, que la crisis ecológica es una demostración de la crisis ética, cultural y espiritual de la modernidad, no se puede pretender sanar la relación con la naturaleza sin sanar todas las relaciones básicas del ser humano: "La apertura a un tú capaz de conocer, amar y dialogar, sigue siendo la gran nobleza de la persona humana" (cf. LS 119).

No obstante, en estos momentos difíciles de la pandemia, existen también presencias llenas de actitudes humanitarias que Francisco (2020c) destaca y alienta:

Hemos redescubierto la importancia del rol del personal de enfermería, como también el de las parteras. Diariamente observamos el testimonio de valentía y sacrificio de los agentes sanitarios, en particular de las enfermeras y enfermeros, quienes con profesionalidad, sacrificio, 
responsabilidad y amor por los demás ayudan a las personas afectadas por el virus, incluso poniendo en riesgo la propia salud. (p. 1)

Asimismo, en ámbito social más pobre de las periferias de la ciudad, surge la solidaridad para afrontar las necesidades básicas para vivir: ollas comunes en donde, cada cual aporta algunos víveres para realizar al menos un almuerzo para los más frágiles de la zona. No es esto lo ideal, pero manifiesta reserva de fraternidad de un pueblo.

Sí, para crecer en humanidad es necesario un esfuerzo fatigoso porque implica un cambio de dirección, de mentalidad, de costumbres, de estilo de vida, de aspiraciones. Pero, ello sólo podrá lograrse preguntándonos ¿quiénes somos? ¿cómo estamos viviendo? ¿a qué estamos llamados? Es necesario entrar en lo profundo del yo para rescatar la propia humanidad del vacío y de la nada.

\section{La Necesidad de un Cambio para Crecer en Humanidad}

La pandemia nos da la oportunidad de cambiar para crecer. En esta línea, comenta Carrón (2020a), sabíamos que éramos vulnerables, pero en tiempos de orgullo tecnológico lo habíamos olvidado, perdiendo la percepción de nuestro ser y de nuestras limitaciones naturales de creaturas (p. 18).

En este sentido, subraya Cuartango (citado en Carrón, 2020a):

Esta peste nos devuelve la conciencia de la fragilidad del ser humano y de su profunda insignificancia frente a las fuerzas de la Naturaleza que no controlamos. Quedemos con la lección de que no somos dioses y que nunca lo seremos. (p. 19)

Se puede decir que éste es el tiempo para crecer en humanidad, el tiempo de la solidaridad, de la atención a los que están en condición de vulnerabilidad.

Por otro lado, la vulnerabilidad se ha puesto de relieve en la injusticia y el abandono de los sistemas sanitarios de varios países.

En realidad, precisa Francisco (2020d), "La tempestad desenmascara nuestra vulnerabilidad y deja al descubierto esas falsas y superfluas seguridades, con las que habíamos construido nuestras agendas, nuestros proyectos rutinas y prioridades" (p. 21).

Ahora se ponen de manifiesto una serie de prácticas, estilos de vida, sentimientos de omnipotencia y de exclusivismos. Esta pandemia no mira ni ricos ni pobres, ni ancianos ni jóvenes o niños, ni primer o tercer mundo, no mira color o raza; todos estamos de la misma manera indefensos ante un pequeño virus que nos puso un tope. Por ello destaca Francisco (2020):

Con la tempestad, se cayó el maquillaje de esos estereotipos con los que disfrazábamos nuestros egos siempre pretenciosos de querer aparentar; y dejó al descubierto, una vez más, esa pertenencia común de la que no podemos ni queremos evadirnos; esa pertenencia de hermanos. (p. 21) 
Trigo (2020) señala que hay que ciertamente, la acción de los gobiernos que han intentado hacerse cargo de la pandemia, pero han llegado a una minoría. La mayoría sigue abandonada a su suerte. La pandemia ha evidenciado la falsa normalidad encubierta en la que la mayoría no cuenta. Tal normalidad es falsa y por su inhumanidad no puede convertirse en norma. Por tanto, no podemos volver a ella; si nos resignamos a la normalidad vigente dejamos de ser humanos porque hemos renunciado a ser hermanos (p. 15).

En realidad, se evidencia un mundo enfermo por el egoísmo, el orgullo la superficialidad. En efecto, agrega Francisco (2020d):

Hemos avanzado rápidamente, sintiéndonos fuertes y capaces de todo. Codiciosos de ganancias, pero nos hemos dejado absorber por lo material y trastornar por la prisa (...) No hemos escuchado el grito de los pobres y de nuestro planeta gravemente enfermo (...) Hemos continuado imperturbables, pensando en mantenernos siempre sanos en un mundo enfermo. (pp. 21-22)

Pero, la necesidad de cambio no es sólo a nivel personal, existe una realidad cultural, en la que priman la ideología y la economía.

\section{Incidencia del Sistema Económico e Ideológico}

No obstante, la pandemia nos apremia para que miremos la realidad en todas sus dimensiones, y nos invitan afrontarlas con la dignidad de los seres humanos, con conciencia, libertad y responsabilidad.

Según Peralta (2020) esta pandemia silenciosamente revela muchas realidades que estaban escondidas en los sistemas económicos, sociales, culturales y políticos en los que vivimos. Manifiesta el silencio cómplice que pone al capital sobre el hombre; descubre a los individualistas y acaparadores. El virus señala los descuidos en la educación, en el cuidado de ancianos, en los derechos del trabajador. Evidencia a los que se aprovechan de la necesidad de otros. Podría decirse que la Covid-19 es el denunciante más eficaz y profético de este tiempo, pero, para ello ha utilizado un método inaceptable que consiste en la muerte de miles de personas (cf. p. 5).

Vitoriano Ribeiro (2020), enfatiza que algunos hombres se sienten fuertes, frente a la sociedad virtual que dominan; pero hay que aprender a mirar la realidad de un minúsculo virus que afecta, destruye vidas, está a la vista. Además, agrega el autor:

La pandemia viral trae también consigo una pandemia ideológica; contamina el capitalismo neoliberal actual. Esa pandemia ideológica crea falsos dilemas, como por ejemplo salvar vidas o economías. Ella contamina nuestra forma de ver al otro, aumentando el racismo contra los orientales, los inmigrantes y los enfermos. El miedo nos cambia ante estos grupos vulnerables de personas. (p. 12)

Por eso, insiste Vitoriano Ribeiro (2020) que la situación actual nos muestra que necesitamos una forma de vida que cultive, aceleradamente, actitudes de 
corresponsabilidad. Es necesaria una sociedad del cuidado colectivo, especialmente de los más vulnerables, ancianos, niños y pobres. Se debe cambiar la forma de vivir y de organizarse: "La sociedad neoliberal tan elogiada, está en cuestión. Percibimos que el neoliberalismo como racionalidad de la organización social, no sirve. (...) Ahora quien salva es el estado (...) es decir, las políticas públicas que pueden ayudarnos a sobrevivir" (p. 13).

A su vez, este es un tiempo de cuestionamiento de ciertas afirmaciones filosóficas. $\mathrm{Al}$ respecto, comenta Carrón (2020a) que la realidad se ha impuesto como alteridad, como una presencia de la que dependemos:

Su irreductibilidad, nos interroga, no nos da tregua. Con Nietzsche nos habíamos convencido de que "no existen hechos solo interpretaciones". Su sentencia ha resistido muchos años como una verdad indiscutible, pero en este momento se muestra débil. Ante nuestros ojos hay algo más que interpretaciones; existen unos hechos contundentes que exigen ser considerados e interpretados. El nihilismo está contra las cuerdas, al menos en este aspecto. (p. 27)

Francisco (2020a), destaca que, en este tiempo, la vida de millones de personas cambió bruscamente. Para mucha gente, permanecer en casa ha sido una oportunidad para detener el frenético ritmo de vida, para estar con los suyos. Pero, para otros es un tiempo de angustia por el futuro incierto, por la inseguridad laboral y por las demás consecuencias de la crisis de la pandemia (p. 2).

Por eso, el Papa Francisco (2020d) llama a tomar, este tiempo crítico como un momento de opción. No es el momento del juicio de Dios, sino de nuestro juicio: un tiempo para elegir lo verdaderamente valioso y lo que es transitorio, para discernir lo que es realmente necesario. Es el tiempo de restablecer la orientación de la vida hacia Dios, y hacia los demás (p. 22).

El Papa apela a un momento de racionalidad y de elección, pero ¿qué es lo que tendríamos que elegir? Elegir cambiar de estilo de vida individualista, consumista; la pandemia no puede dejarnos iguales que antes. Hemos verificado cuánto dependemos unos de otros y que esta "guerra" la vencemos juntos.

Es verdad, habrá quién decida salir del aislamiento para hacer lo mismo de antes; pero, también existe en el hombre, la capacidad de una libertad responsable que piensa y elige otro tipo de vida más humana, más racional, más respetuosa de los otros y del planeta.

\section{Necesidad de un Cambio de Paradigma}

Es pertinente la sugerencia de Muguiro Ibarra (2020). Terminando esta tragedia no debiéramos querer volver a la que llamábamos "normalidad" ni a seguir viviendo ajenos al resto del mundo, encerrados en los privilegiados modos de vida. Ni debiéramos continuar viendo a los inmigrantes con miedo, como enemigos de los que hay que defenderse (p. 5).

Luego de este tiempo de profunda reflexión, lo racional sería no querer volver a la normalidad de la que todo el mundo habla y espera con ansiedad. No debiéramos seguir mirando para otro lado fingiendo que no pasa nada. 
Agrega Muguiro Ibarra (2020):

Siento, que no se habla de lo importante. No se trata de vencer al coronavirus, ni siquiera de cómo voy a sobrevivir este mes. Se trata de cuestionar nuestro estilo de vida para poder seguir sobreviviendo más allá de una década (...) no podemos seguir consumiendo de esta forma, pensando que los recursos son infinitos. (p. 6)

Efectivamente, en estos días de aislamiento, se ha observado la Costa Verde de Lima repleta de diferentes aves, los delfines se acercaron a la orilla y bailaban en fiesta, como festejando nuestra lejanía. En pocas semanas hemos observado cómo el aire, el agua, los animales y las plantas lucían otro aspecto. Se ha hecho patente la destrucción que se está operando en el planeta.

En este sentido, ya lo decía claramente Francisco (2015):

En la modernidad hubo una gran desmesura antropocéntrica que hoy sigue dañando toda referencia común y todo intento de fortalecer los lazos sociales. Por eso, ha llegado el momento de volver a prestar atención a los límites que la naturaleza impone, porque son la posibilidad de un desarrollo humano y social más sano y fecundo. (LS 116)

Porque, continúa diciendo el Papa, que si el hombre se declara autónomo de la realidad se vuelve un dominador absoluto, en consecuencia, la misma base de su existencia se desmorona, porque, en vez de ser colaborador de Dios en la creación, el hombre suplanta a Dios y con ello provoca la rebelión de la naturaleza. No habrá una nueva relación con la naturaleza sin un nuevo ser humano (cf. LS 117).

Por otro lado, habría que agregar lo dicho por Gambaro:

Un tsunami global de esta magnitud no solo cambia las actitudes personales, sino que también tiene repercusiones en las políticas públicas (...) un mal tan radical puede socavar la economía, transformar la democracia, cambiar la esencia de la globalización. En la mayoría de los países del mundo, los gobiernos han respondido a la pandemia con una mezcla de coerción y apoyo económico: por un lado, imponiendo la obligación de quedarse en casa y por otro inyectando miles de millones en el sistema económico para reducir las consecuencias de la crisis. (...) De esta forma, la pandemia ha roto viejos hábitos, y ha aumentado el poder del estado, tanto hacia los ciudadanos como hacia la economía. (Canal Seminarios y Conferencias UCSS, 2020, 00:06:47)

Es decir, el autor señala los cambios en el modo de gestionar la vida política y económica, por el miedo, pueden pasar desapercibidos porque las aceptamos por necesidad.

Jaldemir Vitório (2020) se sitúa en la realidad desde otra perspectiva:

La pandemia es un "signo de los tiempos" que confronta a la humanidad para que busque y encuentre una nueva sabiduría de vida, fundada en la fraternidad, en el cuidado de los más débiles, en la defensa de los derechos de los más pequeños, en atención a la sostenibilidad de la Casa Común. La voz lúcida de los profetas nos invita a discernir, en las entrelíneas de esta 
terrible pandemia, la voz de Dios que nos llama ser más humanos, más fraternos, más solidarios. (p. 31)

Es imprescindible este cambio, se trata de cuidar la vida, por eso finaliza Francisco (2020d) diciendo:

Este no es el tiempo para el egoísmo, porque el desafío que enfrentamos nos une a todos; el virus no hace acepción de personas (...) Es urgente, sobre todo en las circunstancias actuales (...) que todos se reconozcan parte de una única familia y se sostengan mutuamente. (p. 33)

Ciertamente se necesita buscar un nuevo estilo de vida, más sano y sostenible. Quizás se debería aprender la sabiduría ancestral de los pueblos originarios; ella podría contribuir a orientar al mundo hacia un rumbo mejor. La mayoría de estos pueblos tienen una cosmovisión amplia que cuida la armonía en la persona, en la comunidad y en la relación con la naturaleza.

\section{Conclusión}

Se ha comenzado comprendiendo la seriedad y dimensiones de una pandemia globalizada.

Se constataron incoherencias frente a la gravedad de la circunstancia y se observó que, para la mayoría fue una tormenta inesperada.

A su vez, la pandemia de la COVID-19 que puso al descubierto las apariencias de una sociedad considerada "desarrollada" cuando en realidad todavía se manifiesta como una sociedad que se cree omnipotente, discriminadora, individualista, egoísta, usurera, es decir inhumana. Una sociedad que ha perdido la real percepción de su ser y de lo que está llamada a ser.

Progresivamente se ha entendido que es necesario un nuevo tipo de hombre para este tiempo de crisis, un hombre de talla más humana, solidario que construye junto a otros.

Y precisamente, en este contexto el Papa Francisco y otros pensadores, proponen múltiples motivos para aprovechar este tiempo para sugerirnos una dirección y mostrarnos caminos de esperanza en la solidaridad. Se ha verificado la necesidad de que tomemos conciencia de nuestra vulnerabilidad.

Una de las constantes de este momento de pandemia es la evidencia de que no nos salvamos solos, formamos parte de una humanidad. Ya no debe haber lugar para el egoísmo, sino que debemos remar juntos. Asimismo, se advirtió la fragilidad humana de nuestra cultura actual y la necesidad de crecer en solidaridad.

En síntesis, el Papa Francisco y los otros autores señalan una crisis de humanidad que es preciso superar, con un cambio de dirección, de mentalidad, de costumbres, porque la cultura actual, frecuentemente ha mostrado su incapacidad para estar a la altura de las circunstancias.

Por otra parte, es fácil reconocer la importancia del rol que le tocará a la educación, en la gestación de un mundo más humano. Se trata de preocuparse por construir y fortalecer las bases de una nueva sociedad; de una nueva normalidad, es decir adecuada para una vida verdaderamente humana para toda persona que habite este planeta. Todavía hay mucho por hacer para que la vuelta a la "normalidad" no sea una vuelta a una vida sin sentido. 
Se puede concluir con oportunas y poéticas palabras, llenas de verdad, de Gonzáles Buelta (2020):

\section{"PIDAN Y SE LES DARÁ BUSQUEN Y ENCONTRARÁN"}

Pedir y buscar unidos como el inspirar y expirar.

Pedir nos abre al corazón de Dios en su surgir, en su crecer y en su sazón.

Buscar nos activa enteros para salir y encontrar el don que ya crece entre nosotros al ritmo y forma de lo humano.

Dios sabe lo que necesitamos y ya ha empezado a dárnoslo antes de que lo pidamos y es mayor que nuestros sueños.

En los trabajadores enmascarados, los laboratorios en silencio, las rutinas se servidores anónimos, la soledad intubada y muda, el vacío respetuoso de las calles, los templos llenos de ausencias, las cuatro paredes familiares, los muertos al sanar a los heridos, los entierros sin funeral ni llanto, el cálido aplauso de las ocho, y las insomnes redes digitales, ya está creciendo el don impredecible desbordando nuestras oraciones y las predicciones de los sabios.

¿Qué nueva humanidad se está gestando en esta tierra que gime en su embarazo?

No le pidamos a Dios impacientes que presione el vientre de la historia y acelere el parto. Es tiempo de silencio servicial y expectante. (p. 47) 


\section{Referencias}

Carrón, J. (2020a). El despertar de lo humano. Reflexiones de un tiempo vertiginoso. Milán, Italia: BUR Rizzoli [versión e-book]. Recuperado de https://it.clonline.org/cm-files/2020/04/23/eldespertardelohumano.pdf

Carrón, J. (2020b). Un brillo en los ojos. ¿Qué nos arranca de la nada? SL: Fraternitá di Comunione e liberazione [versión e-book] Recuperado de https://espanol.clonline.org/cm-files/2020/07/13/un-brillo-en-los-ojos.pdf

Cela Carbajal, J. (2020). Aprender en tiempos de pandemia. Aurora. Voces jesuitas sobre la pandemia, (2), 20-22. Recuperado de https://issuu.com/ausjal/docs/revista aurora n 2

Concilio Vaticano II. (1965). Gaudium et Spes. Madrid, España: Biblioteca de Autores Cristianos.

Czerny, M. (2020). Prefacio. En Francisco, La vida después de la pandemia (pp. 3-17). Roma, Italia: Librería Editrice Vaticana. Recuperado de https://www.flipsnack.com/director10/la-vida-despu-s-de-la-pandemia.html

Francisco. (2013). Evangelii Gaudium. Sobre el anuncio del evangelio en el mundo actual. Lima, Perú: Ed. Paulinas-Epiconsa.

Francisco. (2015). Laudato sí. Lima, Perú: Oficina de Pastoral Universitaria UCSS.

Francisco. (2018). Mensaje a los participantes de la Conferencia internacional: Los derechos humanos en el mundo contemporáneo: conquistas, omisiones y negaciones. La Santa Sede. Recuperado de http://www.vatican.va/content/francesco/es/messages/pontmessages/2018/documents/papa-francesco_20181210_messaggio-dirittiumani.html

Francisco. (2020a). Mensaje pascual Urbi et Orbi. Basílica Vaticana. Recuperado de http://www.vatican.va/content/francesco/es/messages/urbi/documents/papafrancesco_20200412_urbi-et-orbi-pasqua.html

Francisco. (2020b). Mensaje a las enfermeras. La Santa Sede. Recuperado de http://w2.vatican.va/content/francesco/es/messages/pontmessages/2020/documents/papa-francesco 20200512 messaggio-giornatainfermiere.html

Francisco. (2020c). La vida después de la pandemia. Roma, Italia: Librería Editrice Vaticana. Recuperado de https://www.flipsnack.com/director10/la-vida-despu-sde-la-pandemia.html

Gambaro, G. [Canal Seminarios y Conferencias UCSS] (24 de julio de 2020). I Simposio "Interrogantes y retos antropológicos, éticos y educativos en la crisis de la pandemia" [Archivo de video]. Recuperado de https://www.youtube.com/watch?v=YedYTFV3WCw\&t=575s

Giussani, L. (2008). El sentido religioso. Lima, Perú: Fondo Editorial UCSS, Editorial Encuentro.

Gonzáles Buelta, B. (2020). Pidan y se les dará, busquen y encontrarán. Aurora. Voces jesuitas sobre la pandemia, (2), 47. Recuperado de https://issuu.com/ausjal/docs/revista aurora n 2

López Quintás, A. (1963). Notas de Filosofía. Arquitectura, 5(50), 58-62. Recuperado de https://www.coam.org/media/Default\%20Files/fundacion/biblioteca/revista-

Contacto: revistaeduca@umch.edu.pe ISSN : 2617-0337 revistas.umch.edu.pe/ 
arquitectura-100/1959-1973/docs/revista-completa/revista-arquitectura-1963$\underline{\text { n50.pdf }}$

Jiménez-Bósquez, D. (2020). Lecciones para una nueva humanidad: hacia un nuevo contrato social. Aurora. Voces jesuitas sobre la pandemia, (2), 7-11. Recuperado de https://issuu.com/ausjal/docs/revista_aurora_n_2

Muguiro Ibarra, P. (2020). No quiero volver a la normalidad. Aurora. Voces jesuitas sobre la pandemia, (2), 5-6. Recuperado de https://issuu.com/ausjal/docs/revista aurora n 2

Pablo VI. (1992). Carta encíclica Populorum Progressio. En Irribaren, J. \& Gutiérrez García, J. L. (eds.), Once grandes mensajes (p. 337 Madrid, España: Biblioteca de Autores Cristianos.

Peralta, C. (2020). COVID-19 o el desvelador silente. Aurora. Voces jesuitas sobre la pandemia, (1), 5-8. Recuperado de https://www.flacsi.net/wpcontent/uploads/2020/05/AURORA-REVISTA.pdf

Tolentino de Mendonça, J. (2020). Cuarentena y Pascua. Vida Religiosa, 129(4), 29. Recuperado de https://vidareligiosa.es/wp-content/uploads/2020/04/VR-mes-deabril.pdf

Trigo, P. (2020) Desafíos que nos plantea la pandemia. Aurora. Voces jesuitas sobre la pandemia, (1), 15-17. Recuperado de https://www.flacsi.net/wpcontent/uploads/2020/05/AURORA-REVISTA.pdf

Vitoriano Ribeiro, E. (2020). La pandemia, la filosofía y cada uno de nosotros. Aurora. Voces jesuitas sobre la pandemia, (1), 11-13. Recuperado de https://www.flacsi.net/wp-content/uploads/2020/05/AURORA-REVISTA.pdf

Vitório, J. (2020). La voz lúcida de los profetas en tiempos de COVID-19. Aurora. Voces jesuitas sobre la pandemia, (2), 20-21. Recuperado de https://issuu.com/ausjal/docs/revista_aurora_n_2 